\title{
Numerical Modeling of Doorway Flow Induced by an Air Curtain
}

\author{
Frank K. Lu, ${ }^{*}$ Vijay A. Chauhan, ${ }^{\dagger}$ Adam J. Pierce, ${ }^{\ddagger}$ Takayuki Yajin ${ }^{\ddagger}$ and J. Craig Dutton ${ }^{\S}$ \\ University of Texas at Arlington, Arlington, TX 76019
}

\begin{abstract}
A large cabin was partitioned along its centerline with the two sides were connected by a doorway. An air curtain was mounted just in front of the doorway. Directly below the air curtain, on the floor, is a vent for receiving the air curtain flow. The air curtain flow was modeled by a commercial Reynolds-averaged Navier-Stokes flow solver with a $k$ - $\varepsilon$ turbulence model. The simulation showed that the longitudinal velocity profile of the jet was well maintained from the top to the bottom of the doorway, with a small amount of lateral diffusion. However, the transverse velocity profile showed a larger amount of diffusion. The results indicated that the floor vent did not properly capture the air curtain flow, resulting in entrainment of the air curtain flow into the cabin. Thus, a detailed design of the floor vent is required for certain applications, such as next-generation explosives detection portals, where as much of the air curtain flow as possible needs to be captured.
\end{abstract}

\section{Introduction}

A IR curtains are ubiquitous devices that provide a dynamic barrier instead of a physical barrier between two adjoining areas, thereby allowing easy physical access between them. ${ }^{1,2}$ Air curtains are used as thermal barriers such as vestibule doors for keeping in warm or cold air in large public places and warehouses. ${ }^{3-10}$ They are also popular for isolating refrigerated display cases in supermarkets. ${ }^{11-16}$ Other special uses of air curtains include prevention of smoke propagation, ${ }^{17}$ reduction of fire oxygenation, ${ }^{18,19}$ and contaminant or biological control. ${ }^{20-29}$

Recently, air curtains have been suggested for use in explosive detection portals (EDPs), where a large airflow is used to dislodge particles from a human subject for testing for explosive traces. ${ }^{30}$ In fact, a system based on an air curtain, known as the "Air Jet Explosive Trace Detector," is available commercially. ${ }^{31}$ (For surveys of EDPs, see Refs. 32 and 33.) Such EDPs, using a familiar technology such as air curtains, reduce the intrusiveness of the examination process and may make such devices more acceptable to the general public for use in public places that constitute potential soft targets to terrorists, as exemplified by the subway bombings in Madrid (March 11, 2004) and London (July 7, 2005), and the hotel bombings in Amman (November 9, 2005). Moreover, such portals may be rapidly deployed and can also be used for crowded events, such as festivals. Despite the simplicity of the concept, such "people portal" technology is still in its infancy. ${ }^{34}$

A number of fluid dynamic issues remain to be properly understood to better deploy air curtain-based EDPs, such as the shape and size of the jet, the jet velocity, the turbulence level and the optimal placement of intakes for the explosive sensors. These factors are important to ensure adequate levels of concentration for the explosive sensors, prevent false signals, minimize annoyance and ensure a high volume of human traffic. To address some of these issues, exploratory studies of the complex air curtain flow past a doorway were conducted. These initial studies were conducted with only the bare doorway.

\footnotetext{
* Professor and Director, Aerodynamics Research Center, Mechanical and Aerospace Engineering Department, Box 19018. AIAA Associate Fellow.

${ }^{\dagger}$ Graduate Student, Mechanical and Aerospace Engineering Department, Box 19018; currently, Product and Development Engineer, Flow Design, Inc., Dallas, Texas.

${ }^{\ddagger}$ Undergraduate Research Assistant, Mechanical and Aerospace Engineering Department, Box 19018. AIAA Student Member.

${ }^{\S}$ Professor and Chair, Mechanical and Aerospace Engineering Department, Box 19018. AIAA Associate Fellow.
} 


\section{Methodology}

The air flow analysis was carried out using a commercial software package, FLUENT 6.2. The geometry of the test cabin was input into GAMBIT, FLUENT's geometry and mesh generation software. The problem that was modeled is that of a flow from an air curtain mounted midway at the top of a cabin that is $2.44^{3} \mathrm{~m}^{3}\left(8^{3} \mathrm{ft}^{3}\right)$, as shown in Fig. 1. When viewed from the front, that is, the view presented in Fig. 1, the air curtain is slightly off-center and in front of the symmetry plane, to simulate the physical configuration. ${ }^{35}$ The air curtain is $0.787 \mathrm{~m}$ (31 in.) long by $63.5 \mathrm{~mm}$ (2.5 in.) wide and its opening is $0.38 \mathrm{~m}$ (15 in.) below the cabin ceiling. The air curtain is $5 \mathrm{~cm}(2 \mathrm{in}$.) ahead of the doorway centerline. The air flow is removed from the floor of the cabin by an opening that is directly below the air curtain. This opening is $89 \mathrm{~mm}$ (3.5 in.) wide by $635 \mathrm{~mm}$ (25 in.) long. The air curtain and the floor vent dimensions also replicate the actual physical features of the test cabin. The doorway over which the air curtain is mounted is $3 \mathrm{ft}$ wide and 6.75 feet high. The walls on both sides of the air curtain are $150 \mathrm{~cm}$ (6 in.) thick. The entire cabin is sealed other than the air curtain and the floor vent.

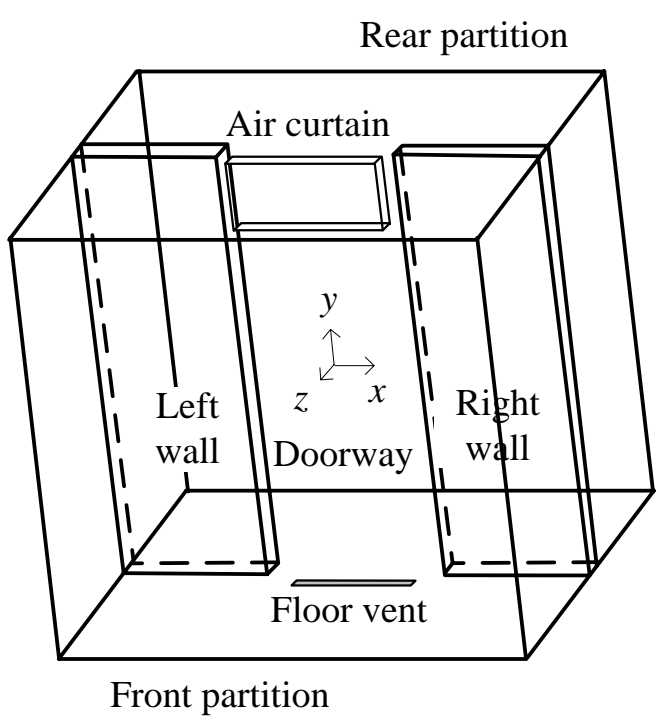

Figure 1. Model configuration showing doorway with air curtain on top and a floor vent at the bottom.

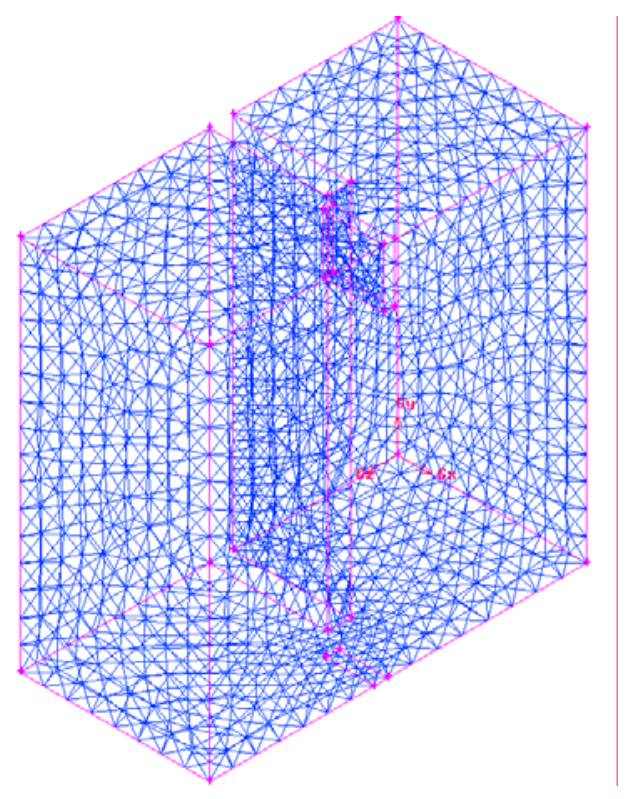

Figure 2. Meshes on left half of the control volume.

Air at one atm and $300 \mathrm{~K}$ leaves the air curtain uniformly with a velocity of $5.34 \mathrm{~m} / \mathrm{s}$. This velocity is representative of air curtain flow velocities. Since actual turbulence data are currently unavailable, for the present simulation, a uniform turbulence intensity of $0.1 \mathrm{~m} / \mathrm{s}$ was used. Finally, Fig. 1 shows the Cartesian coordinate system used in this study. The origin of the coordinates is the center of the cabin.

Once the configuration was developed, a mesh was generated, again using GAMBIT. The boundary conditions were no flow on all the cabin walls. A mass flow rate of $0.331 \mathrm{~kg} / \mathrm{s}$ was imposed on the exit of the air curtain, following specifications of the actual air curtain (Fantech Model A3600).

After the mesh was created and the boundary conditions are set, the data are saved and exported to FLUENT. The Reynolds-averaged Navier-Stokes equations using a $k$ - $\varepsilon$ turbulence mode ${ }^{36}$ were solved for the flow. The computational platform is a Dell Optiplex GX620 with a 3 GHz Pentium 4 processor and 3.50 GB of RAM. A grid refinement study was undertaken to ensure that the computed quantities were properly converged. The results of this study are summarized in Fig. 3 and Table 1. Figure 3 shows an example of the residuals for the 1.5 million grid point case. Convergence can be said to occur after about 7000 iterations. As shown in Table 1, convergence occurs with fewer iterations and in a shorter time for fewer grid points, as expected. Moreover, Table 1 shows that convergence was also reasonable even for the lowest grid count. However, for the present study, 1.5 million grid points were used. 


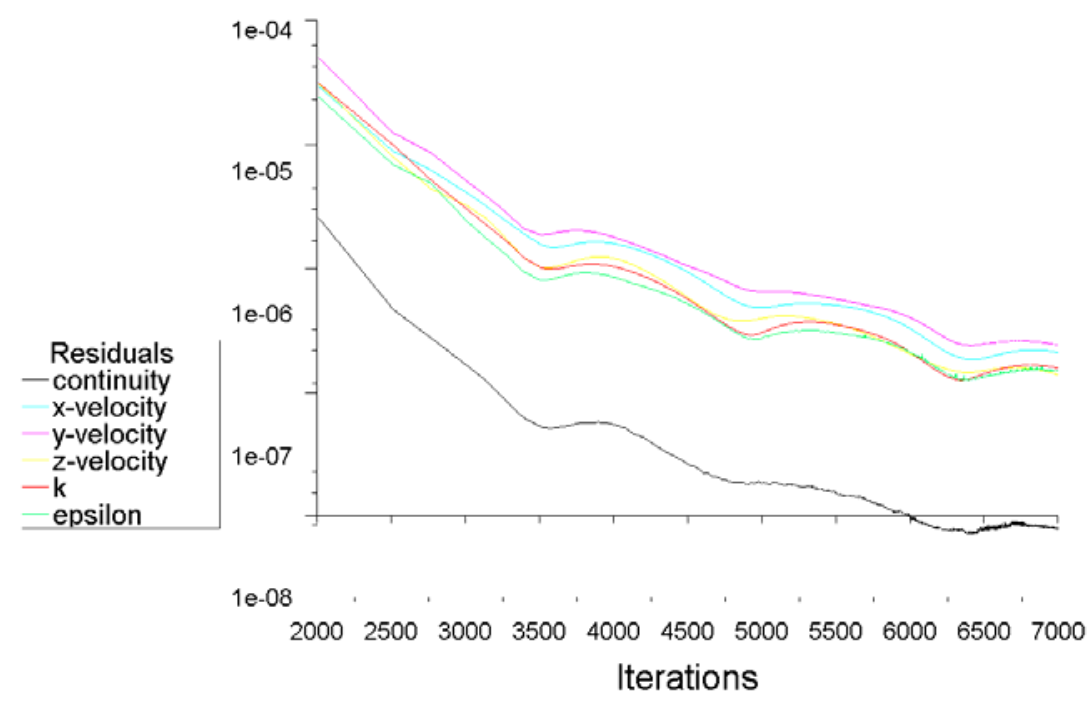

Figure 3. Residuals in computation with 1.5 million grid points.

Table 1. Results of grid convergence study.

\begin{tabular}{|c|c|c|c|c|}
\hline Grid & Iteration & Min. velocity (m/s) & Max. velocity (m/s) & Time(approx) \\
\hline 73968 & 1800 & .003 & 7.787 & 45 minutes \\
\hline 107803 & 1900 & .006 & 7.691 & $1: 30 \mathrm{hr}$ \\
\hline 158707 & 2600 & .005 & 7.904 & $2 \mathrm{hr}$ \\
\hline 252424 & 3400 & .005 & 7.813 & $4 \mathrm{hr}$ \\
\hline 1508910 & 7000 & .002 & 7.651 & $32 \mathrm{hr}$ \\
\hline
\end{tabular}

\section{Results and Discussion}

Doorways, even without air curtains, affect internal air flows, ${ }^{37-41}$ which in turn affect the comfort of the inhabitants, energy usage as well as the transport of trace particles. The addition of an air curtain, which serves to partition two enclosures, complicates the flow pattern. The flow changes from one of natural convection to forced convection, in which the air curtain dominates. Figure 4 shows the velocity vectors of the flow leaving the air curtain and entering the floor vent. The figure shows the uniform flow leaving the air curtain and it shows that the computations captured the slight asymmetry in the flow entering the floor vent due to the slight asymmetry in the placement of the air curtain over the doorway.

Contour plots of the mean total velocity magnitudes along the centerplane of the air curtain and in an orthogonal plane at the left of the floor vent are shown in Fig. 5. The total velocity profiles along the centerplane of the air curtain and in an orthogonal plane at the left of the floor vent are displayed in Fig. 6. In Fig. 6a, the nonuniformities of the flow leaving the air curtain is evident, due to the detailed modeling of the ribs of the exhaust grill. The asymmetry of the air curtain outlet and the floor vent, and their different cross sectional areas, means that the maximum flow velocities at these two stations are different, as is also evident in Figs. 6a and 6b.

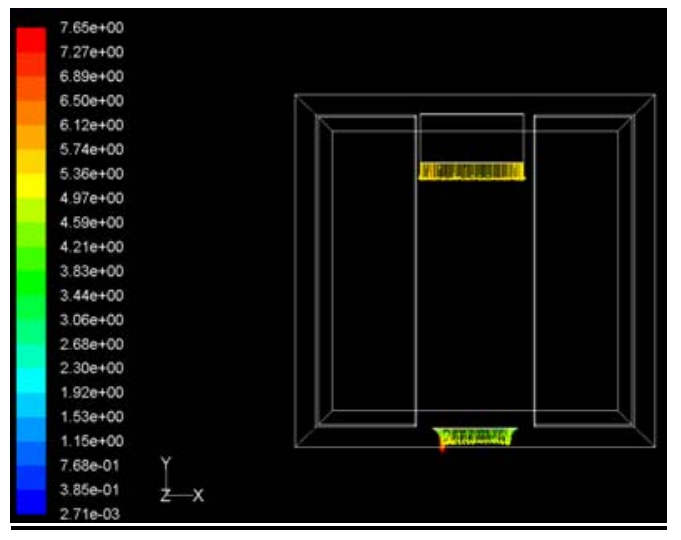

Figure 4. Velocities from the air curtain and floor vent. 


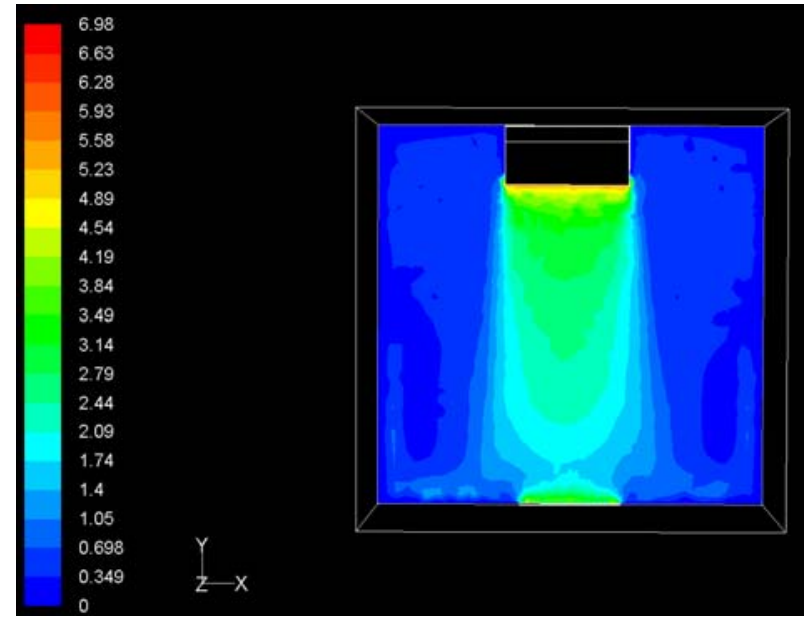

a. Centerplane of air curtain.

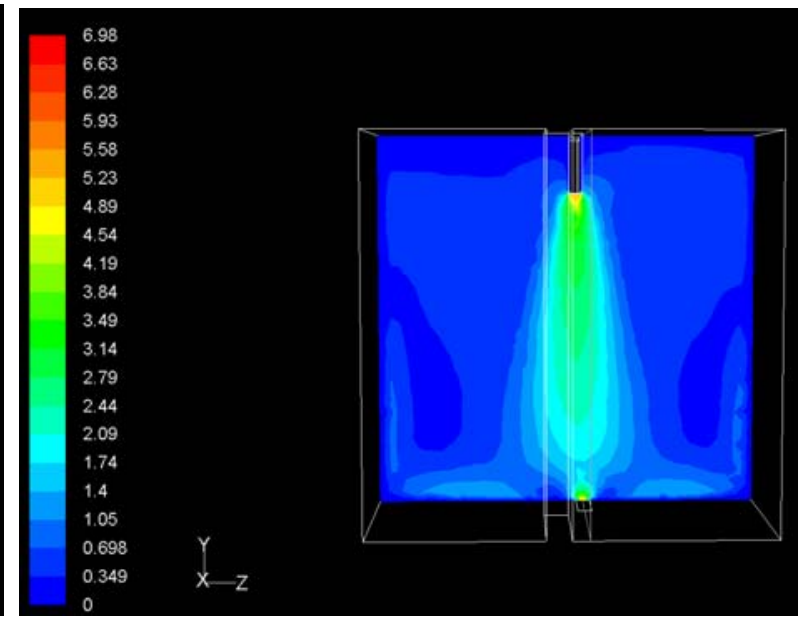

b. Cross plane at left edge of floor vent.

Figure 5. Velocity magnitude of the air curtain $(\mathrm{m} / \mathrm{s})$.

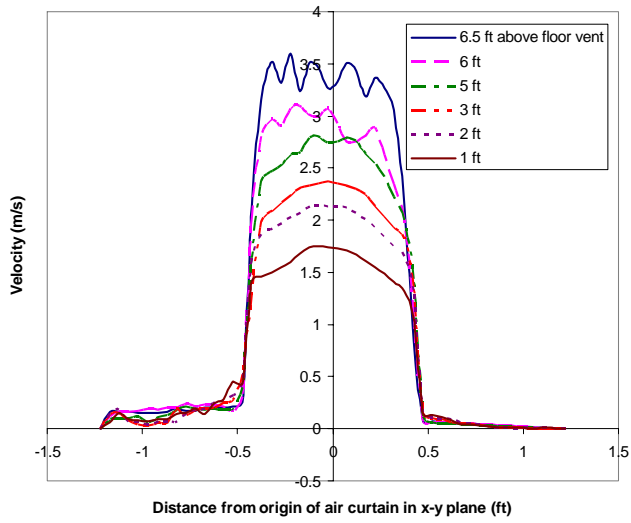

a. Centerline of air curtain.

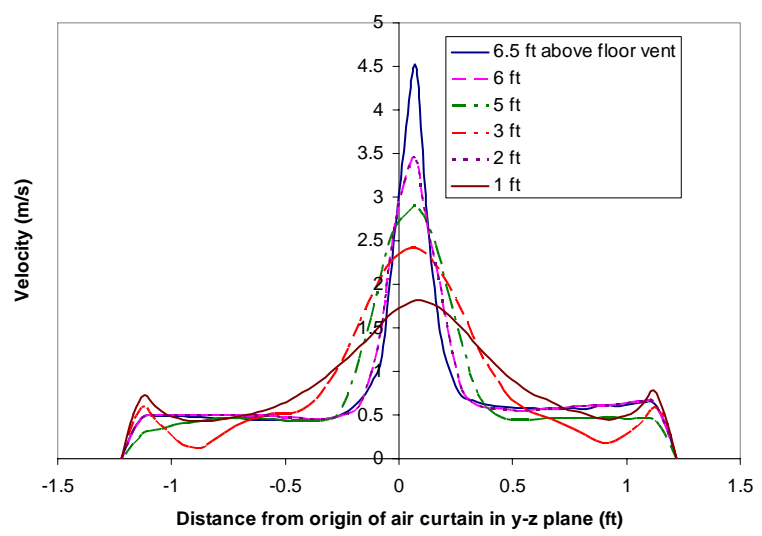

b. Cross plane at left edge of floor vent.

Figure 6. Velocity profiles of the air curtain at various distances from the floor vent.

Figures 5 and 6 show that the jet spreads slower in the $x-y$ plane than in the $z-y$ plane. The figures also show that the present floor vent does not capture the entire mass of the jet. Thus, the recirculating flow also contains a portion of the air curtain jet. This is made more evident in Fig. 7 which shows the mean pathlines along the centerline plane and the cross plane at the left edge of the flor vent of the air curtain. The pathlines indicate entrainment of the ambient air by the air curtain flow. Recirculating flows on either side of the jet are also evident in both planes.

Figures 8 and 9 show plots of the turbulent kinetic energy (TKE) and the turbulent viscosity in the same planes as those of .Figs. 5-7. The TKE plots of Fig. 8 indicate a relatively high level of turbulence at the exit of the air curtain and at the inlet of the floor vent as is to be expected. Figure 8 also shows that the TKE is generally confined within the jet flow of the air curtain. However, the turbulent viscosity does not appear to be as confined, as indicated in the cross-plane distribution in Fig. 9b. The reason for this spread is unclear at the moment.

\section{Conclusions}

A preliminary numerical study of an air curtain flow over a doorway and confined in a cabin was performed using a commercial code. The study found that the air curtain flow was confined well along its longitudinal plane but there was a larger diffusion in the crosswise plane. The study also showed that the location and size of the floor vent must be determined carefully if the bulk of the air curtain flow is to be captured. This has important consequences in the design of next-generation explosive detection portals. 


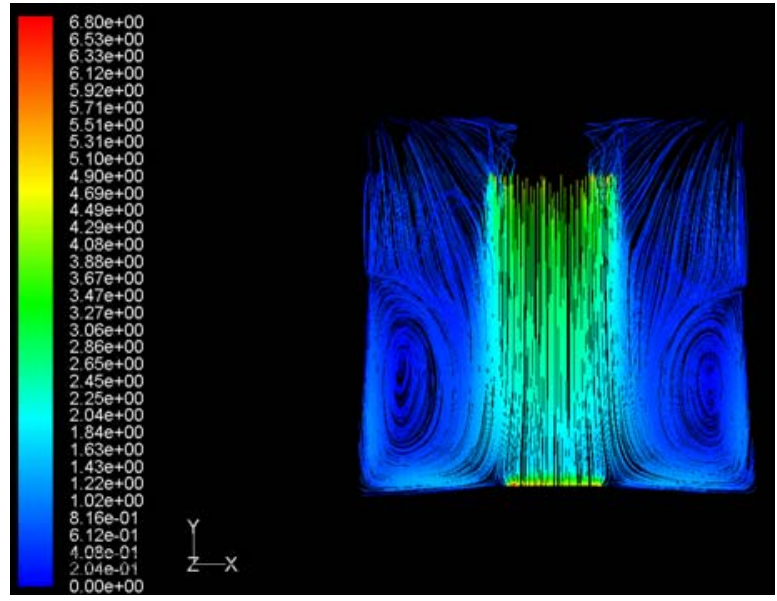

a. Centerplane of air curtain. The scale on the left is of the velocity magnitude in $\mathrm{m} / \mathrm{s}$.

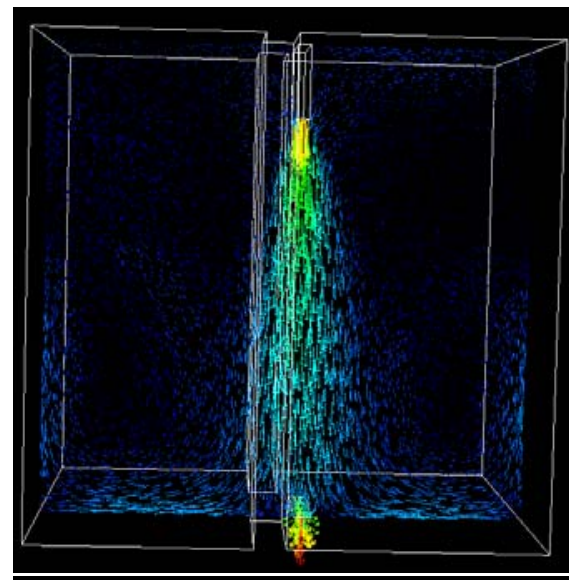

b. Cross plane at left edge of floor vent.

Figure 7. Pathlines along the centerline plane of the air curtain.

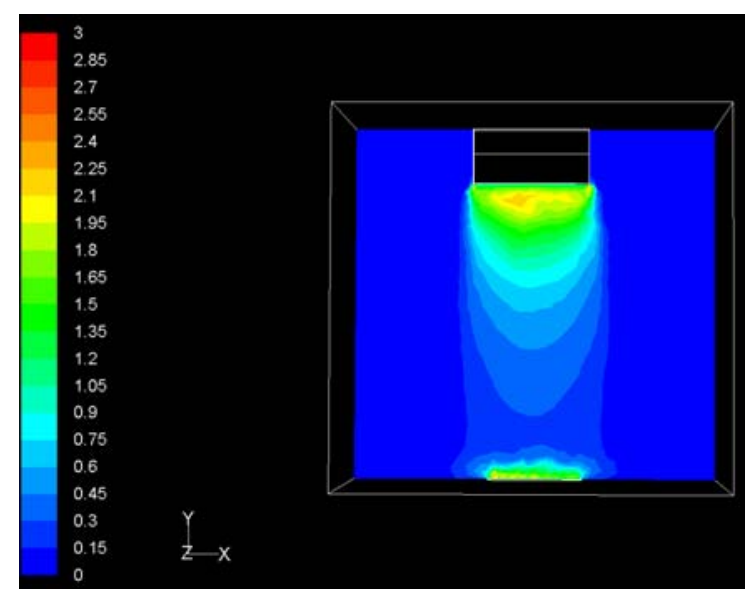

a. Centerplane of air curtain. The scale on the left is of the magnitude of the turbulent kinetic energy in $\mathrm{m}^{2} / \mathrm{s}^{2}$.

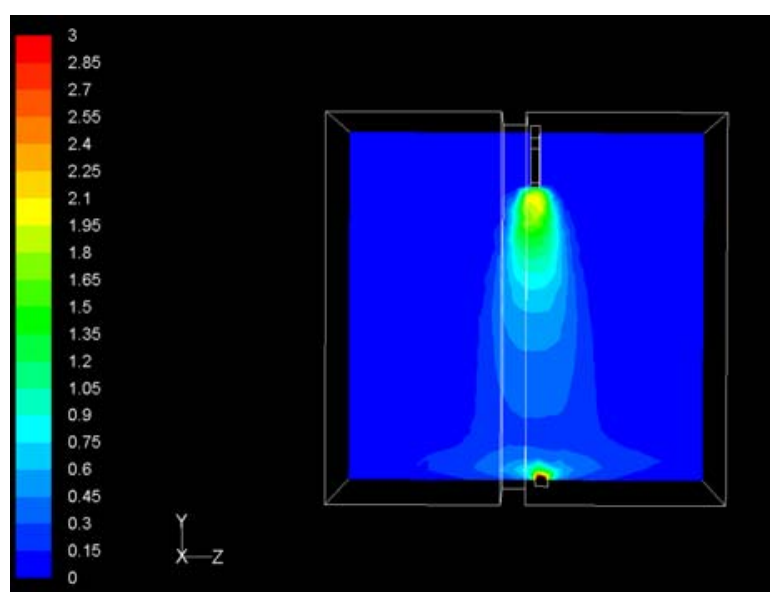

b. Cross plane at left edge of floor vent.

Figure 8. Contour plot of turbulent kinetic energy.

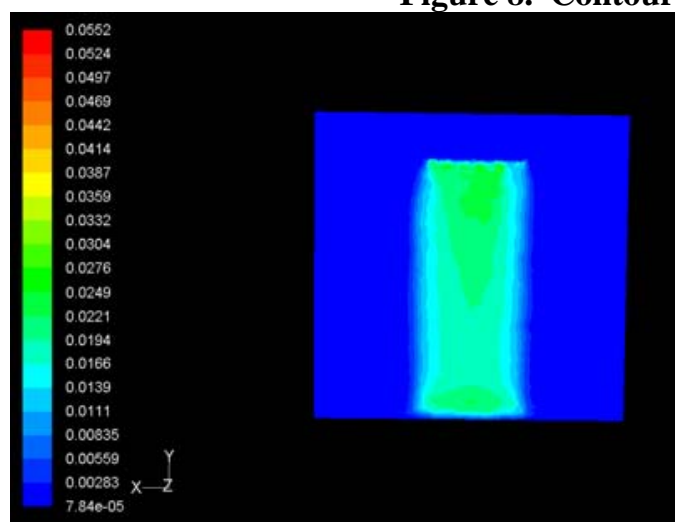

a. Centerplane of air curtain. The scale on the left is in $\mathbf{N} . \mathbf{s} / \mathbf{m}^{2}$.

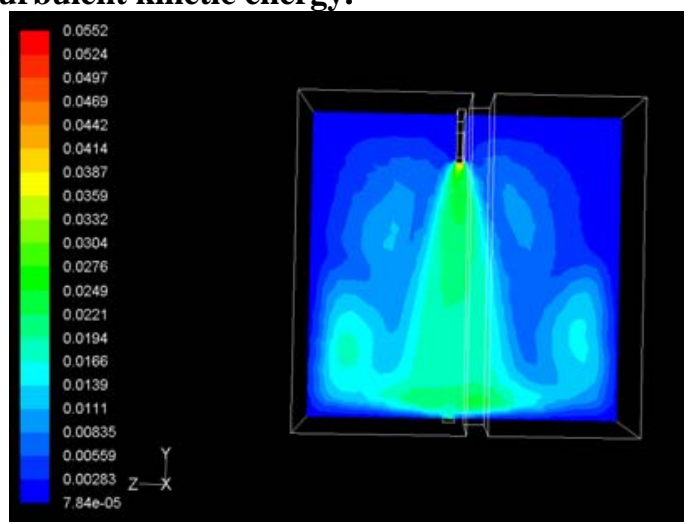

b. Cross plane at left edge of floor vent.

Figure 9. Contour plot of turbulent viscosity. 


\section{Acknowledgments}

The authors thank Richard R. Mitchell for assistance with FLUENT.

\section{References}

${ }^{1}$ Hayes, F. C. and Stoecker, W. F., “Design Data for Air Curtains,” ASHRAE Transactions, Vol. 75, 1969, pp. $168-179$.

${ }^{2}$ Awbi, H. B., Ventilation of Buildings, 2nd ed., 2003, Taylor \& Francis, London.

${ }^{3}$ Hetsroni, G., Hall, C. W. and Dhanak, A.M., "Heat transfer properties of an air curtain," Transactions of the ASAE, Vol. 6, 1963, pp. 328-334.

${ }^{4}$ Van, N. Q. and Howell, R. H., "Influence of Initial Turbulence Intensity on the Development of Plane Air-Curtain Jets," ASHRAE Transactions, Vol. 82, No. 1, 1976, pp. 208-228.

${ }^{5}$ Lawton, E. B. and Howell, R. H., "Energy Savings Using Air Curtains Installed in High-Traffic Doorways,” ASHRAE Transactions, Vol. 101, No. 2, 1995, pp. 136-143.

${ }^{6}$ Clingensmith, A., “Using Air Curtains to Save Energy,” ASHRAE Journal, Vol. 43, No. 11 supplement, 2001, pp. 34-36.

${ }^{7}$ Zhai, Z., Chen, Q., Scanlon, P. W. and Baker, A. J., "Design of a Ventilation System for an Indoor Auto Racing Complex," ASHRAE Transactions, Vol. 108, No. 1, 2002, pp. 989-998.

${ }^{8}$ Pappas, T. C. and Tassou, S. A., "Numerical Investigations into the Performance of Doorway Vertical Air Curtains in AirConditioned Spaces,” ASHRAE Transactions, Vol. 109, No. 1, 2003, pp. 273-279.

${ }^{9}$ Foster, A. M., Swain, M. J., Barrett R. and James, S. J., "Experimental Verification of Analytical and CFD Predictions of Infiltration Through Cold Store Entrances,” International Journal of Refrigeration, Vol. 26, No. 8, 2003, pp. 918-925.

${ }^{10}$ Sirén, K., “Technical Dimensioning of a Vertically Upwards Blowing Air Curtain—Part I,” Energy and Buildings, Vol. 35, No. 7, 2003, pp. 681-695.

${ }^{11}$ Rouaud, O., Havet, M. and Solliec, C., "Influence of External Perturbations on a Minienvironment: Experimental Investigations,” Building and Environment, Vol. 39, No. 7, 2004, pp. 863-872.

${ }^{12}$ Navaz, H. K., Faramarzi, R., Gharib, M., Dabiri, D. and Modarress, D., “The Application of Advanced Methods in Analyzing the Performance of the Air Curtain in a Refrigerated Display Case,” Journal of Fluids Engineering, Vol. 124, No. 3, 2002, pp. 756-764.

${ }^{13}$ Field, B. S. and Loth, E., “An Air Curtain Along a Wall with High Inlet Turbulence,” Journal of Fluids Engineering, Vol. 126, No. 3, 2004, pp. 391-398.

${ }^{14}$ Bhattacharjee, P. and Loth, E., “Entrainment by a Refrigerated Air Curtain Down a Wall,” Journal of Fluids Engineering, Vol. 126, No. 3, 2004, pp. 871-879.

${ }^{15}$ Chen, Y.-G. and Yuan, X.-L., "Experimental Study of the Performance of Single-Band Air Curtains for a Multi-Deck Refrigerated Display Cabinet.” Journal of Food Engineering, Vol. 69, No. 3, 2005, pp. 261-267.

${ }^{16}$ Field, B. S. and Loth, E., "Entrainment of Refrigerated Air Curtains Down a Wall,” Experimental Thermal and Fluid Science, to be published, 2005.

${ }^{17}$ Chow W. K., "Smoke Control by Air Curtain for Spaces Adjacent to Atria,” Journal of Environmental Systems, Vol. 27, No. 2, 1999, pp. 151-162.

${ }^{18}$ Guyonnaud, L., Solliec, C., Dufresne de Virel, M. and Rey, C., "Design of Air Curtains Used for Area Confinement in Tunnels,” Experiments in Fluids, Vol. 28, No. 4, 2000, pp. 377-384.

${ }^{19}$ Gugliermetti, F., Santarpia, G. and Zori, G., “Air curtain applied to fire smoke pollution,” Proceedings of the $11^{\text {th }}$ International Conference on Modelling, Monitoring and Management of Air Pollution, September 17-19, 2003, Catania, Italy, Advances in Air Pollution, pp. 541-549, WIT Press, Billerica, Massachusetts.

${ }^{20}$ Bragg, G. M. and Bednarik, H. V., "Particulate Diffusion Across a Plane Turbulent Jet," International Journal of Heat and Mass Transfer, Vol. 18, No. 3, 1975, pp. 443-451.

${ }^{21}$ Hampl, V., Johnston, O. E. and Murdock, D. J., Jr, “Application of an Air Curtain-Exhaust System at a Milling Process,” American Industrial Hygiene Association Journal, Vol. 49, No. 4, 1988, pp. 167-175.

${ }^{22}$ Etkin, B. and McKinney, W. D., “An Air-Curtain Fume Cabinet,” American Industrial Hygiene Association Journal, Vol. 53, No. 10, 1992, pp. 625-631.

${ }^{23}$ Chen, Q., Jiang, Z. and Moser A., “Control of Airborne Particle Concentration and Draught Risk in an Operating Room,” Indoor Air, Vol. 2, No. 3, 1992, pp. 154-167.

${ }^{24}$ Rydock, J.P., Hestad, T., Haugen, H., Skaret, J.E., “An isothermal air curtain for isolation of smoking areas in restaurants,” in Awbi, H.B., ed., Air Distribution in Rooms, ROOMVENT 2000, Proceedings of the $7^{\text {th }}$ International Conference on Ventilation for Health and Sustainable Environment, 2000, Elsevier.

${ }^{25}$ Pavageau, M., Nieto, E.M. and Rey, C. “Odour and VOC Confining in Large Enclosures Using Air Curtains.” Water Science and Technology, Vol. 44, No. 9, 2001, pp. 165-171.

${ }^{26} \mathrm{Hu}$, S.C., Chuah, Y.K. and Yen, M.C., "Design and Evaluation of a Minienvironment for Semiconductor Manufacture Processes,” Building and Environment, Vol. 37, No. 2, 2002, pp. 201-208.

${ }^{27}$ Ichida, M., Kunitomo, K., Nishimura, T. Sakatani, M., Ueno, H. and Kakiuchi, K., "Ironmaking-Control of $\mathrm{CO}_{2}$ Peak Position by Dual Lance Air Curtain Method,” ISIJ International, Vol. 42, No. 10, 2002, pp. 1077-1083.

${ }^{28}$ Finlayson, E. U., Gadgil, A. J., Thatcher, T. L. and Sextro, R. G., "Pollutant Dispersion in a Large Indoor Space. Part 2: Computational Fluid Dynamics Predictions and Comparison with a Scale Model Experiment for Isothermal Flow. Indoor Air, Vol. 14, No. 4, 2004, pp. 272-283. 
${ }^{29}$ Li, Y., Huang, X., Yu, I. T. S., Wong, T. W. and Qian, H. "Role of Air Distribution in SARS Transmission During the Largest Nosocomial Outbreak in Hong Kong,” Indoor Air, Vol. 15, No. 2, 2005, pp. 83-95.

${ }^{30}$ Parmeter, J. E., Linker, K. L., Rhykerd, C. L., Hannum, D. W. and Bouchier, F. A., "Explosives Detection Portal for HighVolume Personnel Screening," Enforcement and Security Technologies, edited by A. T. DePersia and J. J. Pennella, Proceedings of the SPIE, Vol. 3575, 1998, pp. 384-391.

${ }^{31}$ http://www.hawkajetd.com/

${ }^{32}$ Hallowell, S. F., “Screening People for Illicit Substances: A Survey of Current Portal Technology,” Talanta, Vol. 54, No. 3, 2001, pp. 447-458.

${ }^{33}$ Settles, G. S., "Sniffers: Fluid-Dynamic Sampling for Olfactory Trace Detection in Nature and Homeland Security-The 2004 Freeman Scholar Lecture,” Journal of Fluids Engineering, Vol. 127, No. 2, pp. 189-218, 2005.

${ }^{34}$ Settles, G. S., "Fluid Mechanics and Homeland Security," Annual Review of Fluid Mechanics, Vol. 38, 2006, pp. 87-110.

${ }^{35}$ Pierce, A. J., Yajin, T., Lu, F. K. and Dutton, J. C., "Development of a Facility to Study Large Confined Air Flows,” AIAA Paper 2006-3144, 2006.

${ }^{36}$ Durbin, P. A. and Pettersson Reif, B. A., Statistical Theory and Modeling for Turbulent Flows, Wiley, New York, 2001.

${ }^{37}$ Linden, P. F., “The Fluid Mechanics of Natural Ventilation,” Annual Review of Fluid Mechanics, Vol. 31, 1999, pp. 201238.

${ }^{38}$ Phillips, J. C. and Woods, A. N., “On Ventilation of a Heated Room Through a Single Doorway,” Building and Environment, Vol. 39, No. 3, 2004, pp. 241-253.

${ }^{39}$ Lee, H. and Awbi, H. B., "Effect of Internal Partitioning on Indoor Air Quality of Rooms with Mixing Ventilation-Basic Study,” Building and Environment, Vol. 39, No. 2, 2004, pp. 127-141.

${ }^{40}$ Moureh, J. and Flick, D., “Airflow Characteristics Within a Slot-Ventilated Enclosure,” International Journal of Heat and Fluid Flow, Vol. 26, No. 1, 2005, pp. 12-24.

${ }^{41}$ Ampofo, F., “Turbulent Natural Convection in an Air Filled Partitioned Square Cavity, "International Journal of Heat and Fluid Flow, Vol. 25, No. 1, 2005, pp. 103-114. 